\title{
Chromosome inheritance in triploid Pacific oyster Crassostrea gigas Thunberg
}

\author{
N Gong1,3, H Yang ${ }^{2}$, G Zhang1,2, BJ Landau² and X Guo ${ }^{2}$ \\ ${ }^{1}$ Experimental Marine Biology Laboratory, Institute of Oceanology, Chinese Academy of Sciences, Qingdao, Shandong 266071, PRC; \\ ${ }^{2}$ Haskin Shellfish Research Laboratory, Institute of Marine and Coastal Sciences, Rutgers University, Port Norris, NJ 08349, USA; \\ ${ }^{3}$ The Graduate School of Chinese Academy of Sciences, Beijing 100039, PRC
}

\begin{abstract}
Reproduction and chromosome inheritance in triploid Pacific oyster (Crassostrea gigas Thunberg) were studied in diploid female $\times$ triploid male (DT) and reciprocal (TD) crosses. Relative fecundity of triploid females was $13.4 \%$ of normal diploids. Cumulative survival from fertilized eggs to spat stage was $0.007 \%$ for DT crosses and $0.314 \%$ for TD crosses. Chromosome number analysis was conducted on surviving progeny from DT and TD crosses at 1 and 4 years of age. At Year 1, oysters from DT crosses consisted of $15 \%$ diploids $(2 \mathrm{n}=20)$ and $85 \%$ aneuploids. In contrast, oysters from TD crosses consisted of $57.2 \%$ diploids, $30.9 \%$ triploids $(3 n=30)$ and only $11.9 \%$ aneuploids, suggesting that triploid females produced more euploid gametes and viable progeny
\end{abstract}

than triploid males. Viable aneuploid chromosome numbers included $2 n+1,2 n+2,2 n+3,3 n-2$ and $3 n-1$. There was little change over time in the overall frequency of diploids, triploids and aneuploids. Among aneuploids, oysters with $2 n+3$ and $3 n-2$ chromosomes were observed at Year 1, but absent at Year 4. Triploid progeny were significantly larger than diploids by $79 \%$ in whole body weight and $98 \%$ in meat weight at 4 years of age. Aneuploids were significantly smaller than normal diploids. This study suggests that triploid Pacific oyster is not completely sterile and cannot offer complete containment of cultured populations.

Heredity (2004) 93, 408-415. doi:10.1038/sj.hdy.6800517

Published online 14 July 2004

Keywords: triploidy; aneuploidy; chromosome; sterility; evolution; mollusc

\section{Introduction}

Triploidy has played an important role in the evolution of plants, with allotriploidy often being the first step during polyploidization and speciation (DeWit, 1980). Polyploidization is a prevailing process in plant evolution, and the majority of plants are recent polyploids. Polyploidy is less frequent in the animal kingdom. Polyploidization has clearly occurred in some invertebrate and lower vertebrate taxa (White, 1978; Schultz, 1980; Komaru et al, 2000). It has been suggested recently that two rounds of genome duplication (or tetraploidization) have occurred during the evolution of vertebrates (Furlong and Holland, 2002; Spring, 2002). There is renewed interest in the biology and evolutionary significance of polyploid animals, which is poorly understood at this time.

As a chromosome number mutation, triploidy occurs spontaneously at low frequencies in almost all animal species. While it is lethal or often associated with severe abnormalities in mammals and birds, triploidy is viable and often morphologically indistinguishable from normal diploids in most invertebrates, amphibians and fish (Fankhauser, 1945; Thorgaard, 1983; Komaru et al, 2000). Triploid animals are sterile in some organisms, but produce functional gametes and viable progeny in others.

Correspondence: X Guo, Haskin Shellfish Research Lab, Rutgers University, 6959 Miller Avenue, Port Norris, NJ 08349, USA.

E-mail:xguo@hsrl.rutgers.edu

Received 4 March 2003; accepted 5 May 2004; published online 14 July 2004
If triploids are not completely sterile, what are the genetic and evolutionary consequences of triploidy in animals? Studies on the reproduction and inheritance of triploidy in a variety of animal species may provide some insight.

The Pacific oyster, Crassostrea gigas Thunberg, is a marine bivalve native to the west Pacific, and now cultured in many coastal regions of the world. It is a diploid species without any known history of polyploidization. It is protandric dioecious with rare hermaphroditism (Amemiya, 1929; Guo et al, 1998). Triploidy occurs spontaneously in the Pacific oyster at low but consistent frequencies (Guo et al, 1992; Guo and Allen, 1994a) and as in most other organisms, it can also be artificially induced by blocking meiosis in newly fertilized eggs (Allen et al, 1989). Triploid Pacific oysters are fully viable and morphologically inseparable from diploids, although they have larger body size or faster growth (Allen and Downing, 1986; Guo et al, 1996). Triploids in most molluscs studied so far are bigger than diploids, a common phenomenon that has been referred to as polyploid gigantism (Guo and Allen, 1994b). Despite retarded gonadal development, triploids in most molluscs, including the Pacific oyster, produce mature and functional gametes in at least one sex (Allen, 1987; Komaru and Wada, 1989; Guo, 1991). Gametes produced by triploid Pacific oysters are primarily aneuploid and when fertilized, some of them develop into viable progeny (Guo and Allen, 1994a).

Triploid molluscs are useful for aquaculture production because of their 'sterility', improved meat quality and superior growth. They are widely used for commercial production (Allen et al, 1989; Chew, 1994; Guo et al, 
2001). Triploids are also under development for aquaculture use in several other molluscs. When triploids are completely sterile, the use of triploids for aquaculture may protect biodiversity by preventing escape of cultured stock to wild populations. For triploids that are not sterile, their reproductive potential and genetics are relevant to our understanding of potential impacts of triploids on wild populations. A previous study in the Pacific oyster has provided one estimate of the reproductive potential and gamete chromosome numbers of triploids produced by blocking meiosis (Guo and Allen, 1994a). Here, we provide an estimate of reproductive potential of mated triploid Pacific oysters produced from tetraploids and chromosomal identities of their progeny.

\section{Materials and methods}

\section{Confirmation of triploids by flow cytometry}

Reproduction and chromosome inheritance of triploid Pacific oysters were studied in diploid $\times$ triploid crosses. Triploid Pacific oysters used from this study were produced by diploid female $\times$ tetraploid male mating (Guo et al, 1996). Diploid oysters used were from the same base population that was originally from Washington State and had been maintained at Rutgers University for several generations. Triploid and diploid oysters were 3 years old at the time of spawning. Before making crosses, all triploids were individually certified by flow cytometric analysis (Guo and Allen, 1994a).

\section{Spawn, larval and oyster culture}

Two types of crosses, diploid female $\times$ triploid male (DT) and triploid female $\times$ diploid male (TD), were produced in triplicate. No diploid control was used in this study because of space limitations and the fact we had accumulated considerable data on diploid crosses over the years.

Gametes of the diploid and certified triploid oysters were obtained by dissecting gonads. Eggs were passed through an 80- $\mu \mathrm{m}$ screen, collected and rinsed on a 20$\mu \mathrm{m}$ screen to remove tissue debris. Sperm suspension was passed through a $20-\mu \mathrm{m}$ screen to remove large tissue debris. Since fecundity of triploids was limited, gametes from several triploids were combined for each cross. Filtered $(1 \mu \mathrm{m})$ seawater was used throughout this study. All gamete preparation, fertilization and embryo incubation were conducted at $24-25^{\circ} \mathrm{C}$.

Embryos were cultured in 210-1 tanks according to standard protocols routinely used in our hatchery (Breese and Malouf, 1975). Starting on day 2, larvae were fed with freshly harvested algae, Isochrysis galbana and Chaetoceros calcitrans. Water was changed every other day. When oyster larvae were ready to set, they were treated with epinephrine for the production of cultchless oysters (Coon et al, 1986). Eyed larvae were collected on a 200- $\mu \mathrm{m}$ nytex screen and immersed in a solution of $10^{-4} \mathrm{M}$ epinephrine in seawater for $16 \mathrm{~h}$. Metamorphosed larvae were rinsed and held in downwellers with 200- $\mu \mathrm{m}$ mesh screens until they reached a shell length of about $1 \mathrm{~mm}$, when they were transferred to upweller nursery systems. Survival of fertilized eggs to day 2 (D-stage), day 12 and day 60 (spat) were recorded.
Relative survival of DT and TD crosses was calculated by dividing the survival of DT and TD crosses by the survival of normal diploids. We did not have diploid controls in this study, but used existing survival data for diploid crosses. Under our hatchery conditions, survival of diploid crosses usually varied between 10 and $30 \%$ from fertilized eggs to spat. We used $20 \%$ as the survival for diploid crosses, which is about the same as what was observed in a previous study (Guo and Allen, 1994a).

\section{Chromosome number in surviving oysters}

Chromosome number of surviving oysters was determined at 1 and 4 years of age. A total of 20 oysters were sampled from each replicate of each group. Each oyster was measured (for size), labeled and processed for chromosome number analysis using a protocol similar to Guo and Allen (1994c). Oysters were first kept at 12$15^{\circ} \mathrm{C}$ for $24 \mathrm{~h}$ to synchronize cell divisions. They were then cultured at $23-25^{\circ} \mathrm{C}$ with intensive feeding for $48 \mathrm{~h}$ and subsequently treated with $0.005 \%$ colchicine for $6-$ $10 \mathrm{~h}$. The treated oysters were dissected, and a piece of stomach and gill tissues, about $0.5 \mathrm{~cm}^{3}$, were taken. Tissue samples were treated with $0.075 \mathrm{M} \mathrm{KCl}$ for 10 $20 \mathrm{~min}$ before fixed in Carnoy fixative (1:3 acetic acid and methanol). The fixative was changed three times, and samples were stored at $4{ }^{\circ} \mathrm{C}$. To make cell suspension, a piece of tissue was chopped fine in $50 \%$ acetic acid in water. Three to five drops of cell suspension were dropped onto clean slides and left air-dry. When more spreading was desired, cell suspension was dropped onto slide at $50-53^{\circ} \mathrm{C}$. Then slides were stained with Leishman's stain for about 5-10 min. The working solution was a 1:4 dilution of the stock solution $(100 \mathrm{mg}$ Leishman stain $/ 100 \mathrm{ml}$ methanol) with PBS $(0.025 \mathrm{M}$ $\mathrm{KH}_{2} \mathrm{PO}_{4}, \mathrm{pH}$ 6.8).

The Pacific oyster has a diploid number of 20 chromosomes (Ahmed and Sparks, 1967). Oysters with 20 and 30 chromosomes were considered as euploiddiploid and triploid, respectively. Oysters with any other chromosome number were classified as aneuploids. For each oyster, 10-20 metaphases that show no signs of chromosome loss were counted. A chromosome number was accepted when five to 10 high-quality metaphases from the same oyster showing the same chromosome number. Variation in chromosome number, almost all showing losses, was mostly associated with 'bad' metaphases and considered as artefact from overspreading. Slides were screened with a Nikon ECLIPSE E600 microscope, and photographs were taken using Kodak professional B\&W film with speed set at 100 ASA.

Since oysters were small at 1 year of age, body size was measured only by shell height and whole body weight. At 4 years of age, the following size measurements were collected on each oyster: shell height, shell length, shell width, whole body weight and meat weight. A condition index was calculated as a percent meat weight of whole body weight. Oysters were observed for abnormal morphology and coloration. Body size data for each chromosome number were pooled across groups and analyzed with ANOVA and multiple comparisons of means. Significance level was set at $P<0.05$ unless otherwise noted. 


\section{Results}

\section{Crosses and survival}

A total of 66 confirmed triploids and 16 diploids were used for this study. All triploids sampled except for one were ripe and contained gametes. The triploid oysters consisted of $24(36.4 \%)$ females, $24(36.4 \%)$ males, 17 (25.8\%) hermaphrodites and one $(1.5 \%)$ individual without gametes. The diploid oysters consisted of six (37.5\%) females and $10(62.5 \%)$ males.

The number of parents used, number of eggs fertilized, fertilization level and percent survival to day 2 (D-stage), day 12 (eyed stage) and day 60 (spat) are presented in Table 1. Six diploid females were used for three DT groups, producing 49.1 million eggs or 8.2 million per female. A total of 21 triploid females were used in three TD groups, and they produced 23.4 million eggs, averaging 1.1 million per female. The relative fecundity of triploid females was $13.4 \%$ of that of normal diploids.

There was no difference in fertilization level between DT and TD crosses. Fertilization levels in DT and TD groups were 79 and $85 \%$, respectively. Survival of fertilized eggs to day 2 (D-stage) was $21.2 \%$ in TD and $6.8 \%$ in DT groups, both lower than the $60-80 \%$ expected for normal diploids under our hatchery conditions. Most of larval mortality occurred during the first week. One DT group, DT2, suffered complete mortality before reaching spat stage. Cumulative survival to day 60 (spat) stage was $0.007 \%$ for DT groups and $0.314 \%$ for TD groups. Two-sample $t$-test using transformed percentage data showed that survival to spat of TD was significantly higher than that of DT groups $(P=0.006)$. Relative survival of DT and TD groups was 0.035 and $1.57 \%$, respectively, of the normal diploid rate (assumed to be $20 \%$ ).

Spat survived well after metamorphosis. Cumulative survival of spat to 3 years of age was $63.1 \%$ for two DT groups and $78.7 \%$ for three TD groups. TD2 and TD3 were accidentally lost in Year 3 (not due to mortality), and only TD1 was available for chromosome analysis at Year 4.

\section{Chromosome number}

At Year 1, chromosome number was successfully determined for 99 of the 100 oysters sampled $(20 \times 5$ groups). One individual in TD2 did not produce enough metaphases. In the DT groups, the majority of oysters $(85 \%)$ had aneuploid chromosome numbers (Table 2). In

Table 1 Number of parents used (for gamete pooling), number of eggs fertilized, percent fertilization and cumulative survival of fertilized eggs to day 2 (D-stage), day 12 and day 60 (spat stage) in diploid female $\times$ triploid male (DT) and reciprocal (TD) crosses in the Pacific oyster

\begin{tabular}{|c|c|c|c|c|c|c|c|}
\hline \multirow[t]{2}{*}{ Group } & \multicolumn{2}{|c|}{ Number of parents } & \multirow{2}{*}{$\begin{array}{l}\text { Egg no. } \\
\left(\times 10^{6}\right)\end{array}$} & \multirow{2}{*}{$\begin{array}{c}\text { Fertilization } \\
(\%)\end{array}$} & \multicolumn{3}{|c|}{ Survival (\%) } \\
\hline & Maternal & Paternal & & & Day 2 & Day 12 & Day 60 \\
\hline DT1 & $1(2 n)$ & $6(3 n)$ & 21.4 & 88 & 5.9 & 0.2 & 0.004 \\
\hline DT2 & $3(2 n)$ & $4(3 n)$ & 17.4 & 69 & 2.8 & 0.1 & 0 \\
\hline DT3 & $2(2 n)$ & $8(3 n)$ & 10.3 & 81 & 11.6 & 2.6 & 0.017 \\
\hline Mean & 2 & 6 & 16.4 & 79 & 6.8 & 1.0 & 0.007 \\
\hline TD1 & $6(3 n)$ & $1(2 n)$ & 6.6 & 94 & 6.5 & 5.2 & 0.242 \\
\hline TD2 & $6(3 n)$ & $1(2 n)$ & 6.2 & 75 & 43.9 & 8.2 & 0.522 \\
\hline TD3 & $9(3 n)$ & $1(2 n)$ & 10.6 & 86 & 13.1 & 2.2 & 0.179 \\
\hline Mean & 7 & 1 & 7.8 & 85 & 21.2 & 5.2 & 0.314 \\
\hline
\end{tabular}

Table 2 Chromosome number composition (\%) of Pacific oysters produced from diploid female $\times$ triploid male (DT) and reciprocal (TD) crosses observed at Year 1 and Year 4 of age

\begin{tabular}{|c|c|c|c|c|c|c|c|c|c|c|c|c|c|}
\hline \multirow[t]{2}{*}{ Group } & \multirow[t]{2}{*}{$\mathrm{N}$} & \multicolumn{7}{|c|}{ Chromosome number } & \multicolumn{5}{|c|}{ Group summary } \\
\hline & & 20 & 21 & 22 & 23 & 28 & 29 & 30 & $20-23$ & $28-30$ & $A n$ & $A n / 2 \mathrm{n}$ & $A n / 3 \mathrm{n}$ \\
\hline \multicolumn{14}{|l|}{ Year 1} \\
\hline DT1 & 20 & 20.0 & 35.0 & 30.0 & 15.0 & 0 & 0 & 0 & 100.0 & 0 & 80.0 & 80.0 & 0 \\
\hline DT3 & 20 & 10.0 & $25.0^{\mathrm{a}}$ & 45.0 & 5.0 & 10.0 & 5.0 & 0 & 85.0 & 15.0 & 90.0 & 75.0 & 15.0 \\
\hline Mean & & 15.0 & 30.0 & 37.5 & 10.0 & 5.0 & 2.5 & 0 & 92.5 & 7.5 & 85.0 & 77.5 & 7.5 \\
\hline TD1 & 20 & 60.0 & 10.0 & 0 & 0 & 5.0 & 5.0 & 20.0 & 70.0 & 30.0 & 20.0 & 10.0 & 10.0 \\
\hline TD2 & 19 & 31.6 & 5.3 & 0 & 0 & 0 & 10.5 & 52.6 & 36.8 & 63.1 & 15.8 & 5.3 & 10.5 \\
\hline TD3 & 20 & 80.0 & 0 & 0 & 0 & 0 & 0 & 20.0 & 80.0 & 20.0 & 0 & 0 & 0 \\
\hline Mean & & 57.2 & 5.1 & 0.0 & 0.0 & 1.7 & 5.2 & 30.9 & 62.3 & 37.7 & 11.9 & 5.1 & 6.8 \\
\hline \multicolumn{14}{|l|}{ Year 4} \\
\hline DT1 & 13 & 7.7 & 61.5 & 30.8 & 0 & 0 & 0 & 0 & 100.0 & 0 & 92.3 & 92.3 & 0 \\
\hline DT3 & 24 & 25.0 & 58.3 & 12.5 & 0 & 0 & 4.2 & 0 & 95.8 & 4.2 & 75.0 & 70.8 & 4.2 \\
\hline Mean & & 16.4 & 59.9 & 21.7 & 0 & 0 & 2.1 & 0 & 97.9 & 2.1 & 83.7 & 81.6 & 2.1 \\
\hline TD1 & 17 & 47.1 & 0 & 0 & 0 & 0 & 11.8 & $41.2^{\mathrm{b}}$ & 47.1 & 53.0 & 11.8 & 0 & 11.8 \\
\hline
\end{tabular}

ancluding one $21 / 26$ mosaic.

'Including one 20/30 mosaic.

The diploid number in this species is 20, and aneuploids (An) at diploid and triploid levels were labeled as An/2n and An/3n, respectively. 
DT1, four of the 20 oysters (20\%) sampled had the diploid number of 20 chromosomes, and the other 16 $(80 \%)$ were aneuploids: seven with $21(2 n+1$, trisomic), six with $22(2 n+2)$ and three with $23(2 n+3)$ chromosomes. No triploids or hypotriploids were observed. In DT3, two of the 20 oysters (10\%) were diploid, and all others $(90 \%)$ were aneuploids. A total of 15 of the aneuploids were hyperdiploids with 21, 22 and 23 chromosomes. One oyster in DT3 was a mosaic for 21/ 26 chromosomes. Three of the aneuploids were hypotriploids: two with $28(3 n-2)$ and one with $29(3 n-1)$ chromosomes. Representative metaphases are present in Figure 1.

The majority $(88.1 \%)$ of oysters from TD groups were euploid, and aneuploids only accounted for $11.9 \%$ of the TD oysters analyzed (Table 2). Among the euploids, about two-thirds (57.2\% of the total) had 20 chromosomes, and about other third $(30.9 \%$ of the total) were triploids with 30 chromosomes. There were some variations among the three TD groups in the frequency of chromosome number observed. TD3 had primarily diploids and no aneuploids, while TD2 had more triploids than diploids. TD1 had frequencies that were similar to group means. Among the seven aneuploids observed in TD groups, three were trisomics $(2 n+1)$ and four were hypotriploids $(3 n-1,3 n-2)$. Overall, it was clear that TD groups produced more euploids $(88.1 \%)$ and fewer aneuploids (11.9\%) than DT groups (15 and
$85 \%$, respectively), and the difference is highly significant $\left(\chi^{2}, P<0.0001\right)$.

At Year 4, chromosome number was successfully determined for 54 oysters: 13 for DT1, 24 for DT3 and 17 for TD1 (Table 2). Several oysters in DT1 suffered unexpected mortality before chromosome analysis. Overall, the number of diploid, triploid and aneuploid oysters observed at Year 4 were similar to that observed at Year 1 (Figure 2). For DT groups, frequencies of diploid, triploid and aneuploid oysters at Year 4 were 16.4, 0 and $83.7 \%$, respectively, compared with 15.0, 0 and $85 \%$ at Year 1. Within the aneuploid group, however, there was a noticeable change in frequencies of different aneuploid chromosome numbers. Aneuploids with 23 and 29 chromosomes were observed at Year 1, but disappeared in Year 4 . The frequency of oysters with 22 chromosomes decreased, while the frequency of trisomics increased. In TD1, the frequency of triploids increased. Some of the changes may be incidental due to sampling error.

\section{Chromosome number and body size}

Shell height and whole body weight of 1-year old oysters are grouped by chromosome numbers and presented in Table 3. ANOVA revealed significant effects of chromosome number on body size (ANOVA, $P<0.001$ ). Triploids (30 chromosomes) were significantly bigger than diploids (20 chromosomes) in both shell height (by 18\%)

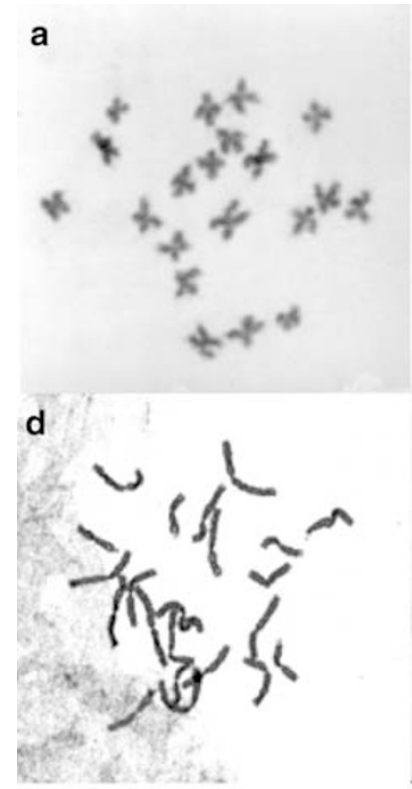

b

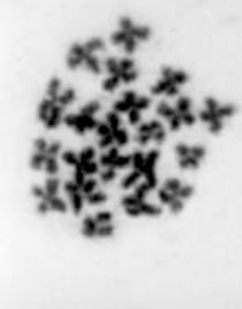

e

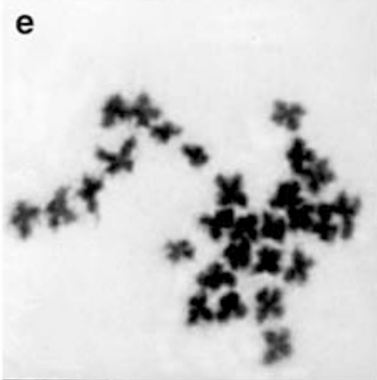

f

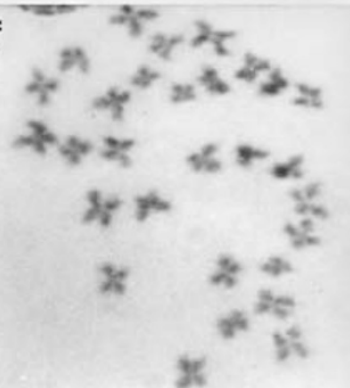

C

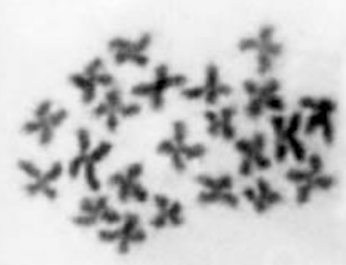

g

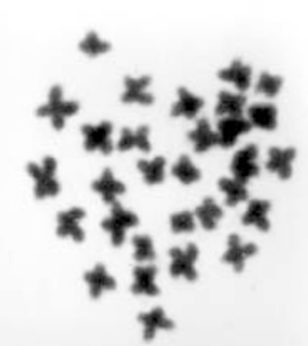

Figure 1 Representative metaphases of diploid, triploid and aneuploid Pacific oysters produced from diploid $\times$ triploid crosses: (a) $2 n=20$; (b) $2 n+1=21$; (c), $2 n+2=22$; (d), $2 n+3=23$; (e), $3 n-2=28$; (f) $3 n-1=29$; (g) $3 n=30$ chromosomes. 
412
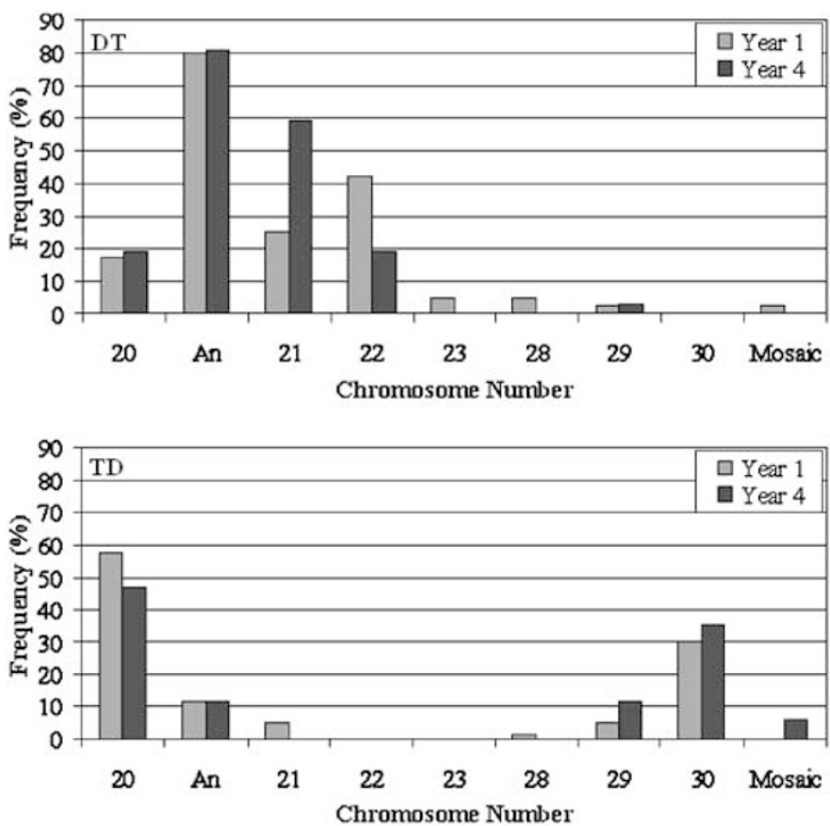

Figure 2 Frequency of oysters with different chromosome numbers produced from diploid female $\times$ triploid male (DT) and reciprocal (TD) crosses in the Pacific oyster observed at Year 1 and Year 4. An refers to all aneuploids combined.

Table 3 Body size $( \pm S E)$ by chromosome number of oysters produced from diploid $\times$ triploid crosses measured at 1 year of age

\begin{tabular}{lrcc}
\hline Chromosome & $\mathrm{N}$ & Length $(\mathrm{mm})$ & Whole weight $(\mathrm{g})$ \\
\hline 20 & 39 & $33 \pm 2^{\mathrm{b}}$ & $3.4 \pm 0.5^{\mathrm{b}}$ \\
21 & 15 & $25 \pm 3^{\mathrm{c}}$ & $2.3 \pm 0.5^{\mathrm{bc}}$ \\
22 & 15 & $19 \pm 2^{\mathrm{c}}$ & $1.0 \pm 0.2^{\mathrm{c}}$ \\
23 & 4 & $19 \pm 2^{\mathrm{c}}$ & $0.9 \pm 0.2^{\mathrm{b}}$ \\
28 & 4 & $31 \pm 4^{\mathrm{abc}}$ & $3.0 \pm 0.9^{\mathrm{abc}}$ \\
29 & 4 & $23 \pm 3^{\mathrm{bc}}$ & $1.1 \pm 0.3^{\mathrm{bc}}$ \\
30 & 18 & $39 \pm 3^{\mathrm{a}}$ & $5.6 \pm 1.3^{\mathrm{a}}$ \\
\hline
\end{tabular}

Groups that do not share any letter are significantly different from each other.

and whole body weight (by 65\%). Hyperdiploids were significantly smaller than normal diploids in shell height. In body weight, oysters with 22 chromosomes were smaller than diploids, while the other hyperdiploids were not significantly different from diploids. The lack of significant difference is probably due to the small number of aneuploids observed.

Body size measurements by chromosome number of 4year old oysters are presented in Table 4. Effects of chromosome number on body size at Year 4 were highly significant in all measurements (ANOVA, $P<0.001$ or $P<0.0001$ ). Diploid oysters measured $70 \mathrm{~mm}$ in shell height, $42.4 \mathrm{~g}$ in whole body weight and $9.3 \mathrm{~g}$ in wet tissue weight. Triploids were significantly bigger than diploids in all measurements except in condition index. Triploid gigantism (percent increase over diploids) was $23 \%$ in shell height, $24 \%$ in shell length, $23 \%$ in shell width, $79 \%$ in whole body weight and $98 \%$ in meat weight. Hyperdiploids were significantly smaller than normal diploids in all direct measurements. In condition index, oysters with 22 chromosomes were smaller than diploids, while trisomics were not significantly different from diploids. Oysters with 29 chromosomes were significantly smaller than triploids, despite the small sample size. Aneuploids, when combined into a single group $(n=42)$, were significantly smaller than diploids in all measurements $(P<0.01)$.

Although aneuploids and triploids differed significantly from diploids in group means, there was considerable variation in body size within each chromosome number group (Table 1 and 4). Most chromosome number groups overlapped each other in size. Further, we could not detect any visible phenotypic difference among diploid, triploid and aneuploid oysters. Sampling at Year 1 was conducted during the spawning season, and all oysters sampled showed close to normal levels of gonadal development for 1-year old oysters. It was not possible to distinguish triploids and aneuploids from diploids by the appearance of gonads alone.

\section{Discussion}

\section{Reproductive potential of triploids}

This study confirms early observations that triploid Pacific oysters produce functional gametes (Allen, 1987; Guo, 1991) and viable offspring (Guo and Allen, 1994a). The relative fecundity of triploid females observed in this study, $13.4 \%$, is higher than the $2 \%$ observed in the previous study (Guo and Allen, 1994a). Triploids used in the previous study were produced from diploids by blocking polar body II. Triploids used in this study were mated triploids from diploid $\times$ tetraploid mating, and the tetraploids were produced from selected triploid females with high fecundity (Guo and Allen, 1994c). The mated triploids may have inherited genes responsible for high fecundity in triploids through their highly fecund triploid grandmothers. Despite the artificial selection on fecundity through the triploid grandmother, reproductive potential of mated triploids is relevant because they are being used for commercial aquaculture production (Guo et al, 2001).

Survival to spat of TD crosses $(0.314 \%)$ was about 44 times higher than that of DT crosses $(0.007 \%)$. The same pattern was observed in the previous study, where TD groups survived 65 times better than DT crosses (Guo

Table 4 Body size $( \pm S E)$ by chromosome number of oysters produced from diploid $\times$ triploid crosses measured at 4 years of age

\begin{tabular}{|c|c|c|c|c|c|c|c|}
\hline Chromosome & $\mathrm{N}$ & Height (mm) & Length (mm) & Width (mm) & Whole wt(g) & Meat $w t(g)$ & $C I(\%)$ \\
\hline 20 & 15 & $70 \pm 2^{\mathrm{b}}$ & $38 \pm 2^{b}$ & $22 \pm 1^{b}$ & $42.4 \pm 4.2^{\mathrm{b}}$ & $9.3 \pm 1.0^{\mathrm{b}}$ & $21.9 \pm 0.6^{\mathrm{a}}$ \\
\hline 21 & 22 & $54 \pm 3^{c}$ & $33 \pm 1^{c}$ & $18 \pm 1^{c}$ & $27.9 \pm 3.0^{c}$ & $5.6 \pm 0.6^{c}$ & $20.0 \pm 0.6^{\mathrm{b}}$ \\
\hline 22 & 7 & $50 \pm 3^{c}$ & $30 \pm 3^{c}$ & $18 \pm 1^{c}$ & $19.8 \pm 3.8^{c}$ & $3.3 \pm 0.6^{c}$ & $16.9 \pm 1.2^{\mathrm{c}}$ \\
\hline 29 & 3 & $59 \pm 7^{b c}$ & $33 \pm 3^{b c}$ & $19 \pm 3^{\mathrm{bc}}$ & $26.5 \pm 7.6^{\mathrm{bc}}$ & $5.9 \pm 1.9^{\mathrm{bc}}$ & $21.4 \pm 1.3^{\mathrm{ab}}$ \\
\hline 30 & 6 & $86 \pm 4^{\mathrm{a}}$ & $47 \pm 2^{\mathrm{a}}$ & $27 \pm 2^{\mathrm{a}}$ & $75.7 \pm 9.6^{\mathrm{a}}$ & $18.4 \pm 2.5^{\mathrm{a}}$ & $24.1 \pm 0.7^{\mathrm{a}}$ \\
\hline
\end{tabular}

Groups that do not share any letter are significantly different from each other. 
and Allen, 1994a). This observation is not accidental and may be a reflection of real differences in chromosome inheritance between triploid females and males (see below). Assuming that triploid males have about the same relative fecundity as triploid females (13.4\%), reproductive potential of triploids in DT and TD mating is about 0.0046 and $0.2104 \%$. On average, triploids have a relative reproductive potential of $0.1075 \%$ (about 1 / 1000), when mated with normal diploids. The reproductive potential estimated here is higher than the previous estimate of $0.0046 \%$ or 1 in 22000 (Guo and Allen, 1994a). The difference is partly due to the increased fecundity (by about seven-fold) of mated triploids and partly due to increased survival. Larval survival is variable, and estimates provided here are provisional and for hatchery conditions only. Nevertheless, this study provides the first estimate of the reproductive potential of mated triploids produced from tetraploids. The use of existing diploid data may be an additional source of variation, but it should not affect the magnitude of the estimates. It is clear that triploid Pacific oysters are fertile, and more estimates are needed for an accurate understanding of their reproductive potential.

\section{Chromosomal inheritance}

The finding of aneuploids among progeny from DT and TD crosses is not surprising. Triploid Pacific oysters produce primarily aneuploid gametes with an approximately normal distribution of chromosome numbers between $10(1 n)$ and $20(2 n)$ and around a mean of 15 (1.5n) (Guo and Allen, 1994a). It has been shown that the Pacific oyster tolerates a variety of chromosome numbers including: $2 n-1,2 n+1,3 n-2,3 n-1,3 n, 3 n+1,3 n+2$, $3 n+3,4 n-2,4 n-1,4 n$ and $4 n+1$ (Guo and Allen, 1994c; Wang et al, 1999). This study adds two more viable chromosome numbers, $2 n+2$ and $2 n+3$, to the list of viable chromosome numbers in this species. Since DT and TD crosses cover all possible chromosome number variation between $2 n$ and $3 n$, the absence of chromosome numbers between 24 and 27 suggests that they are lethal in the Pacific oyster. It seems that the Pacific oyster can tolerate aneuploidy with two-chromosome additions and one-chromosome loss to its diploid genome. Similarly, the pearl oyster Pinctada martensii can tolerate twochromosome gains to its diploid genome (He et al, 2000). Drosophila can tolerate about $10 \%$ chromosome gain and $3 \%$ chromosome loss, and human for $6 \%$ gain and $3 \%$ loss (Hecht and Hecht, 1987).

A new and rather surprising finding from this study is that oysters from DT crosses were primarily aneuploid $(85 \%)$, while oysters from TD crosses were primarily diploid and triploid (88\%). Triploids with 30 chromosomes accounted for $30.9 \%$ of oysters from TD crosses, but were absent in DT crosses. These differences suggest that chromosome inheritance differs significantly between triploid females and males. Triploid females somehow produced more diploids and triploids than triploid males, which produced more aneuploids. There is no comparable data in the literature. In a previous study, triploid females produced more triploid progeny than triploid males when mated with diploids (Guo and Allen, 1994a), but the ploidy was determined by flow cytometry, which was not sensitive enough to detect aneuploids. Guo and Allen (1994a) have suggested that meiotic segregation in triploid males is accurate and produces strictly aneuploid gametes by random segregation of the three sets of chromosomes; they propose that segregation in eggs, on the other hand, is selective, favoring the production of euploid gametes. Our data seem to support Guo and Allen's hypothesis.

The difference in chromosome inheritance between triploid females and males explains the observation that TD crosses survived 44 times better than DT crosses. TD crosses survived better than DT crosses, probably because of the production of euploid progeny.

\section{Chromosome number and body size}

Results of this study demonstrate that chromosome number significantly affects body size in the Pacific oyster. Triploids are significantly bigger than diploids, while aneuploids are significantly smaller than diploids. Triploids have been produced and evaluated in over 20 species of molluscs and in most species studied so far, triploids are bigger than diploids (Guo et al, 2001). This phenomenon has been referred to as triploid gigantism, and several hypotheses have been advanced attributing triploid gigantism to sterility, increased heterozygosity or larger size of triploid cells (Guo and Allen, 1994b). The level of triploid gigantism observed here, $79 \%$ in whole body weight and $98 \%$ in meat weight, is among the highest reported for this and other species. Triploid gigantism is generally between 30 and 50\% in most species studied so far (Guo, 1999). The data presented here are robust, considering that oysters were measured before ploidy determination and the comparisons were made within groups.

Aneuploidy or hyperdiploidy has a negative effect on body size in the Pacific oyster as has been shown in other organisms. In human, most trisomics are lethal, and Trisomy 21 (Down Syndrome) causes growth and mental retardation. In the pearl oyster Pinctada martensii (Dunker), aneuploids or hyperdiploids $(2 n \pm 1$ and $2 n \pm 2)$ were also smaller than diploids (He et al, 2000). No comparable data exist in the Pacific oyster. Aneuploids at the triploid level were not significantly different from triploids, probably due to small sample size (Wang et al, 1999). Negative correlations between somatic aneuploidy (or hypodiploidy) and growth has been reported in the Pacific oyster (Thiriot-Quievreux et al, 1988; Zouros et al, 1996; Leitao et al, 2001). Zouros et al (1996) has proposed that the negative correlation between aneuploidy and growth is caused by unmasking of deleterious genes from progressive haploidization or chromosome loss. The observation in this study, that hyperdiploids are also smaller than normal diploids, argues against the unmasking hypothesis. The fact that the addition of a complete set of chromosomes in triploidy has no negative effects on body size, supports that prevailing hypothesis that aneuploidy negatively affects body size because of altered gene dosages or regulating systems (Guo and Birchler, 1994). Furthermore, we saw no evidence in this and other studies that somatic hypodiploidy was a real phenomenon. Loss of chromosomes is a common artifact of chromosome spreading by airdrying. In our experience, chromosome loss is apparently associated with 'bad' metaphases, and metaphases of high quality rarely show hypodiploid chromosome numbers (Wang et al, 1999). 
Evolutionary and practical implications

It is clear that triploid Pacific oysters are not sterile. The reproductive potential of one in 1000 is small for a given individual, but may be significant at evolutionary scales. Triploids produce diploid, triploid and aneuploid progeny when mated with normal diploids. A previous study has shown that fertile tetraploids can arise from triploid $\times$ triploid crosses (Guo and Allen, 1994a). Triploids are not only viable and vigorous, but also have a size advantage over normal diploids. It is possible that triploidy, which occurs spontaneously in most organisms, represents a 'chromosome lottery' in evolution and possibly leads to the emergence of triploids, tetraploids and other new chromosome numbers. It is unknown to what extent triploidy has contributed to chromosome number changes in molluscs, but the results of this study suggest that such a possibility exists. The evolutionary significance of triploidy is probably limited in Crassostrea oysters, since all species studied so far had a haploid number of 10 chromosomes (Nakamura, 1985). However, triploidy is not an evolutionary dead end in the Pacific oyster and probably not in most other mollusks either. In other groups of molluscs, variation in chromosome number is common, and triploid species exist along with diploids (Patterson, 1969; Komaru et al, 2000).

Owing to their superior growth and 'perceived' sterility, triploids are being used for aquaculture production and field evaluation of non-native species. Most molluscs are cultured in open marine systems. Triploids, when completely sterile, can be used for the containment of non-native species or genetic-modified strains/organisms. In the Pacific oyster and probably most molluscs, triploids are not completely sterile and cannot provide complete containment. Since triploids have greatly reduced reproductive potential compared with diploid stocks, the use of triploids in aquaculture can still reduce 'genetic pollution' of wild populations by selected strains. On the other hands, the production of aneuploid progeny is unwanted. When large populations of triploids are deployed for aquaculture production, they could affect chromosome number of wild populations.

\section{Acknowledgements}

We thank Mr Gregory DeBrosse for help with animal care and Dr Yongping Wang with data presentation. This work was supported by grants from USDA (96-352053854), National Sea Grant (R/TAG-9969) and New Jersey Commission on Science and Technology (02-2042-00711). Work in China is supported by grants from China's Natural Science Foundation (39825121 and 39970590). This is Publication IMCS-04-56 and Sea Grant publication NJSG-04-561.

\section{References}

Ahmed M, Sparks AK (1967). A preliminary study of chromosomes of two species of oysters (Ostrea lurida and Crassostrea gigas). J Fish Res Board Can 24: 2155-2159.

Allen Jr SK (1987). Reproductive Sterility of Triploid Shellfish and Fish. PhD Dissertation, University of Washington.

Allen Jr SK, Downing SL (1986). Performance of triploid Pacific oysters, Crassostrea gigas (Thunberg). I. Survival, growth, glycogen content, and sexual maturation in yearlings. J Exp Mar Biol Ecol 102: 197-208.
Allen Jr SK, Downing SL, Chew KK (1989). Hatchery Manual for Producing Triploid Oysters. University of Washington Press: Seattle.

Amemiya I (1929). On the sex change of the Japanese oyster, Ostrea gigas Thunberg. Proc Imp Acad Tokyo 5: 284-286.

Breese WP, Malouf RE (1975). Hatchery Manual for the Pacific Oyster Oregon State University Sea Grant College Program, Publication no. ORESU-H-75002: Corvallis.

Chew KK (1994). Tetraploid Pacific oysters offer promise to future production of triploids. Aquacult Mag 20: 69-74.

Coon SL, Bonar DB, Weiner RM (1986). Chemical production of cultchless spat using epinephrine and norepinephrine. Aquaculture 58: 255-262.

DeWit JMJ (1980). Origins of polyploids. In: WH Lewis (ed) Polyploidy, Biological Relevance. Plenum Press: New York, pp 3-15.

Fankhauser G (1945). The effects of changes in chromosome number on amphibian development. Quart Rev Biol 20: 20-78.

Furlong RF, Holland PWH (2002). Were vertebrates octoploid? Philos T Roy Soc B 357: 531-544.

Guo M, Birchler JA (1994). Trans-acting dosage effects on the expression of model gene systems in maize aneuploids. Science 266: 1999-2002.

Guo X (1991). Studies on Tetraploid Induction in the Pacific oyster, Crassostrea gigas (Thunberg). PhD Dissertation, University of Washington.

Guo X (1999). Superior growth as a general feature of triploid shellfish: evidence and possible causes. J Shellfish Res 18: 266-267.

Guo X, Allen Jr SK (1994a). Reproductive potential and genetics of triploid Pacific oyster, Crassostrea gigas (Thunberg). Biol Bull 187: 309-318.

Guo X, Allen Jr SK (1994b). Sex determination and polyploid gigantism in the dwarf surfclam (Mulinia lateralis Say). Genetics 138: 1199-1206.

Guo X, Allen Jr SK (1994c). Viable tetraploids in the Pacific oyster (Crassostrea gigas Thunberg) produced by inhibiting polar body I in eggs from triploids. Mol Mar Biol Biotechnol 3: 42-50.

Guo X, Cooper K, Hershberger WK, Chew KK (1992). Genetic consequences of blocking polar body I with cytochalasin B in fertilized eggs of the Pacific oyster, Crassostrea gigas: I. Ploidy of resultant embryos. Biol Bull 183: 381-386.

Guo X, DeBrosse G, Allen Jr SK (1996). All-triploid Pacific oysters (Crassostrea gigas Thunberg) produced by mating tetraploids and diploids. Aquaculture 142: 149-161.

Guo X, Hedgecock D, Hershberger WK, Cooper K, Allen Jr SK (1998). Genetic determinants of protandric sex in Crassostrea oyster. Evolution 52: 394-402.

Guo X, Yang H, Kraeuter J (2001). Triploid and tetraploid technology for hard clam aquaculture. Jersey Shoreline 20: 6-9.

He M, Lin Y, Shen Q, Hu J, Jiang W (2000). Production of tetraploid pearl oyster (Pinctada martensii Dunker) by inhibiting the first poplar body in eggs from triploids. J Shellfish Res 19: 147-151.

Hecht F, Hecht BK (1987). Aneuploidy in human: dimensions, demography, and dangers of abnormal numbers of chromosomes. In: BK Vig, AA Sandberg (eds) Aneuploidy Part A: Incidence and Etiology. Alan R Liss, Inc.: New York, pp 9-49.

Komaru A, Ookubo K, Kiyomoto M (2000). All meiotic chromosomes and both centrosomes at single pole in the zygotes discarded as two polar bodies in clam Corbicula leana: unusual polar body formation observed by antitubulin immunofluorescence. Dev Genes Evol 210: 263-269.

Komaru A, Wada KT (1989). Gametogenesis and growth of induced triploid scallops Clamys nobilis. Nippon Suisan Gakkaishi 55: 447-452 (in Japanese with English abstract).

Leitao A, Boudry P, Thriot-Quievreux C (2001). Negative correlation between aneuploid and growth in the Pacific oyster Crassostrea gigas Thunberg: ten years of evidence. Aquaculture 193: 39-48. 
Nakamura HK (1985). A review of molluscan cytogenetic information based on the CISMOCH-computerized index system for molluscan chromosomes. Bivalvia, Polyplacophora and Cephalopoda. Venus Jpn J Malacol 44: 193-226.

Patterson CM (1969). Chromosomes of molluscs. Proceedings of the Symposium on Mollusca Held at Cochin Part II. Marine Biology Association of India: Mandapam Camp, pp 635-686.

Schultz RJ (1980). Role of polyploidy in the evolution of fishes. In: WH Lewis (ed) Polyploidy, Biological Relevance. Plenum Press: New York, pp 313-340.

Spring J (2002). Genome duplication strikes back. Nat Genet 31: 128-129.

Thiriot-Quievreux C, Neol T, Bougrier S, Dollot S (1988). Relationship between aneuploidy and growth rate in pair mating of the oyster, Crassostrea gigas. Aquaculture 75: 89-96.

Thorgaard GH (1983). Chromosome set manipulation and sex control in fish. In: WS Hoar, DJ Randall, EM Donaldson (eds) Fish Physiol. Academic Press: London, pp 405-434.

Wang Z, Guo X, Allen Jr SK, Wang R (1999). Aneuploid Pacific oyster (Crassostrea gigas Thunberg) as incidentals from triploid production. Aquaculture 173: 347-357.

White MJD (1978). Modes of Speciation. W.H. Freeman and Company: San Francisco.

Zouros E, Thiriot-Quievreux C, Kotoulas G (1996). The negative correlation between somatic aneuploidy and growth in the oyster Crassostrea gigas and implications for the effects of induced polyploidization. Genet Res Camb 68: 109-116. 